\title{
EFFECTIVENESS EVALUATION OF THE DAMAGE LOCALIZATION WITH A LOCAL SPATIAL FILTRATION UNDER VARIABLE EXTERNAL CONDITIONS
}

\section{Krzysztof MENDROK, Magda BOCHEŃSKA, Ziemowit DWORAKOWSKI}

AGH University of Science and Technology, Department of Robotics and Mechatronics, al. Mickiewicza 30, 30-059 Krakow, Poland, e-mail: mendrok@agh.edu.pl

Summary

One of the biggest issues in damage detection and structural health monitoring is the influence of the ambient conditions changes on the operation of the algorithms. Very often the impact is similar to the one generated by fault and it results in false alarm. A lot of effort was put into trying to make these influences independent. The presented article shows the autonomous method, which allows to distinguish the influence of ambient temperature from damage on local spatial filtration. The idea is tested on both numerical and experimental data.

Keywords: Ambient temperature, local spatial filter, damage detection, autonomous classification, spatial group measurement

\section{OCENA SKUTECZNOŚCI LOKALIZACJI USZKODZEŃ METODĄ LOKALNEJ FILTRACJI PRZESTRZENNEJ PRZY ZMIENNYCH WARUNKACH ZEWNĘTRZNYCH}

Streszczenie

Jednym z ważniejszych zagadnień w wykrywaniu uszkodzeń i układach monitorowania stanu obiektów jest wpływ zmian warunków zewnętrznych na działanie algorytmu. Bardzo często wspomniane oddziaływanie jest podobne do tego, które jest generowane przez uszkodzenie i może wywoływać fałszywe alarmy. Poświęcono dużo wysiłku w próby uniezależnienia tych wpływów. Prezentowany artykuł prezentuje autonomiczną metodę, która pozwala rozróżniać wpływy temperatury zewnętrznej od uszkodzenia na lokalną filtrację modalną. Pomysł był zweryfikowany przy pomocy danych numerycznych jak i eksperymentalnych.

Słowa kluczowe: temperatura zewnętrzna, lokalne filtry modalne, wykrywanie uszkodzeń, klasyfikator autonomiczny

\section{INTRODUCTION}

An effective structural condition monitoring system should work in a continuous mode and not generate false alarms. False alarm provides an information about the damage when it actually do not appear, and only the detection algorithm has been deceived. Such an alarm causes loss of trust to the system by the service staff and results in ignoring subsequent notifications (although these may carry the right information). The factor that most affects the proper functioning of the monitoring systems is the change in the ambient temperature. Its impact may result in the symptom parameter shift comparable with the one caused by damage. For example the civil engineering structures during the summer time are exposed to the high air temperature amplified by sun operation. The stiffness of the object drops with temperature, what further brings natural frequency decrease. For that reason, an effective application of the structural health monitoring system based on natural frequencies of the structure requires application of some method to distinguish the effect of temperature from damage. There are some papers where attempt is made to determine the influence of outside temperature on the SHM system operation. In part of applications a lookup table is prepared, in which fault symptoms, identified for different ambient temperatures, are gathered together. Such a table is unique and must be prepared individually for monitored object as a result of set of simulations or experiments. More sophisticated method for elimination of the temperature influence on the monitoring system efficiency is application of socalled environmental filter [1]. It is generally an autoregressive model with moving average (ARMA) identified from a set of experimental data. Another example can be found in [2]. On the basis of long-term observation of temperature changes and the resulting variations in natural frequency, the authors calculated the correlation between the temperature (obtained as the average for 10,000 time samples) and the natural frequency. This is basically a lookup table approach. As an alternative method, the authors proposed tracking natural frequencies at variable temperatures corrected by an environmental filter with a more complex structure in the form of an output error model from the Box Jenkins models group. In paper [3] the changes of 
modal parameters caused by ambient temperature were assessed to adjust modal data used for damage detection. First, a set of experiments was done, to estimate temperature effect on modal properties. On the basis of the obtained data the empirical frequency-correction relationship between temperature and natural frequencies was formed. Next, an ordinary frequency-based damagedetection method was used to detect damage. Principal Component Analysis to deal with environmental changes and their influence on damage detection was applied in [4]. The method did not require any measurement of ambient temperature because it was considered as embedded variable. It effect can be observed from the variation of the identified features. Extension of the approach to Kernel PCA can be found in [5]. A statistical parametric damage detection algorithm based on a null space residual associated with output-only subspace identification extended to account for the temperature effect can be found in [6]. The extension has two levels. First a thermal model for deriving a temperature-adjusted null space is used. Second the thermal model together with a statistical nuisance rejection technique is exploited. In [7] artificial neural network was applied to deal with ambient temperature effect. First, a correlation between modal parameters and temperature was formulated with the backpropagation neural network technique. With the correlation model, the modal parameters identified for different temperature conditions were normalized to an identical reference status of temperature to eliminate the temperature effect. The normalized modal parameters were next applied for damage detection. Similar problems with temperature changes can be obviously experienced also in high frequency damage detection techniques e.g. with use of Lamb waves. Also here some methods can be found to eliminate the effect $[8,9$, 10, 11]. In particular, a Spatial Group Measurement (SGM) approach was presented and verified in this area [10]. The method utilizes the fact that damage is expected to influence the structure locally while changes caused by environmental factors tend to be global.

The presented paper shows the method of automatic distinction between temperature and damage without any correction algorithms or temperature effect filtration. The approach is based on interpretation of the results of the standard method using the SGM approach. The idea is tested on both numerical and experimental data.

\section{THE IDEA OF THE TEMPERATURE EFFECT ELIMINATION IN LOCAL MODAL FILTERS}

Application of modal filtration in damage detection has itself a high degree of robustness to temperature changes. In the work [13] it was shown that the change of the ambient temperature by 30
${ }^{\circ} \mathrm{C}$ for a simple frame structure causes a much smaller disturbance of the modal filter operation than the $10 \%$ damage. However, a larger temperature change (which is possible even in moderate climatic zones) or a more complex geometry of the monitored structure, can lead to false alarms, that is a spurious detection of damage by the algorithm caused by the change in the ambient temperature.

The new idea of temperature effect elimination is based on the application of local modal filters for damage detection and localization [14]. It can also help to distinguish other effects like mass variations due to monitored object exploitation (e.g. traffic on the bridge deck). Authors claim, that there will be different responses on the consecutive local modal filters for different cases. The single damage will result in significant growth of the damage index (DI) value only for one local filter or its closest surrounding. The ambient temperature change will also change the response of filtration but the reaction should be observed on all local filters. Also the moving mass is expected to have different effect on the levels of DIs than damage. These differences may be exploited by application of an autonomous method that will be able to distinguish between different cases of damage, load or ambient factors.

In the next sections the idea of local modal filters and their application to damage localization is briefly recalled, and further the new idea is tested on the previously described frame model both numerically and experimentally.

\section{LOCAL MODAL FILTERS}

In this chapter a method of local modal filtration for damage localization [14] is briefly recalled. The method is based on the fact that damage disturbs the mode shapes locally [15]. In this approach a monitored object is divided into areas where vibrations are measured with the use of a few sensors only. A separate local modal filters are built for data coming from these sensors. In areas without damage, the shape of modes does not change significantly and the local modal filters keep working. When a group of sensors located in the area of the damage is considered, mode shape is there disturbed and the filter does not work perfectly. Due to the fact, that the method is based on the detection of disturbances in spatial filter operation (the appearance of badly filtered peaks on the output filter characteristics), the method may not work properly for objects with high modal density, and in particular for multiple poles.

The graphical presentation of the method's idea is shown in Figure 1.

In order to parameterize the damage localization results, the Damage Index DI was calculated for each area. It is given by Formula (1): 


$$
D I=\frac{\int_{\omega_{S}}^{\omega_{f}}\left|x_{i}(\omega)-x_{r e f}(\omega)\right|^{2} d \omega}{\int_{\omega_{s}}^{\omega_{f}} x_{r e f}(\omega)^{2} d \omega}
$$

where:

$\omega_{s}$ - starting frequency of the analyzed band,

$\omega_{f}$ - closing frequency of the analyzed band,

$x_{i}$ - characteristic in the current state,

$x_{r e f}$ - characteristic in the reference state.

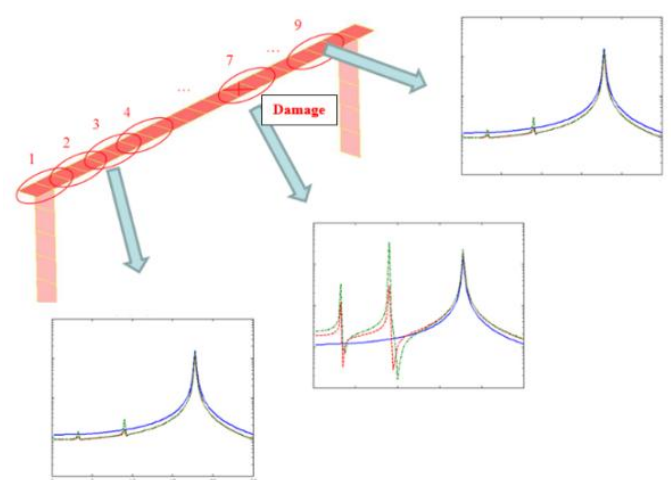

Fig. 1. Scheme of the applied method of damage localization

The DI is computed only for the frequency bands directly surrounding the natural frequencies of the monitored object, except the one to which the modal filter is set. Authors propose to use $2-6 \mathrm{~Hz}$ surrounding of the natural frequencies depending on the value of the damping coefficient of a given mode.

For the convenience of interpretation, the results are presented in the form of bar charts, where the amplitude of successive bars is the DI value for subsequent areas.

\section{SPATIAL GROUP MEASUREMENT}

In most damage monitoring scenarios faults in structures are required to be detected at an early stage of their growth. Due to that they tend to influence the structure only locally. On the other hand, changes caused by environmental factors are expected to be observed uniformly in the whole structure. The locality of change can thus be measured and used as a general health indicator of the whole structure $\mathrm{DI}_{\mathrm{SGM}}(2)$.

where:

$$
\mathrm{DI}_{\mathrm{SGM}}=\mathrm{DI}_{\max }-\mathrm{DI}_{\text {median }}
$$

$\mathrm{DI}_{\max }$ - maximal local damage indication,

$\mathrm{DI}_{\text {median }}$ - median of all local damage indications

The rationale behind the equation is that the more the $\mathrm{DI}_{\max }$ stands out of the typical (e.g. median) observation, the more local the change is. This is further illustrated in fig. 2 where expected values for intact state, local damage and global change caused by environmental factors are provided.
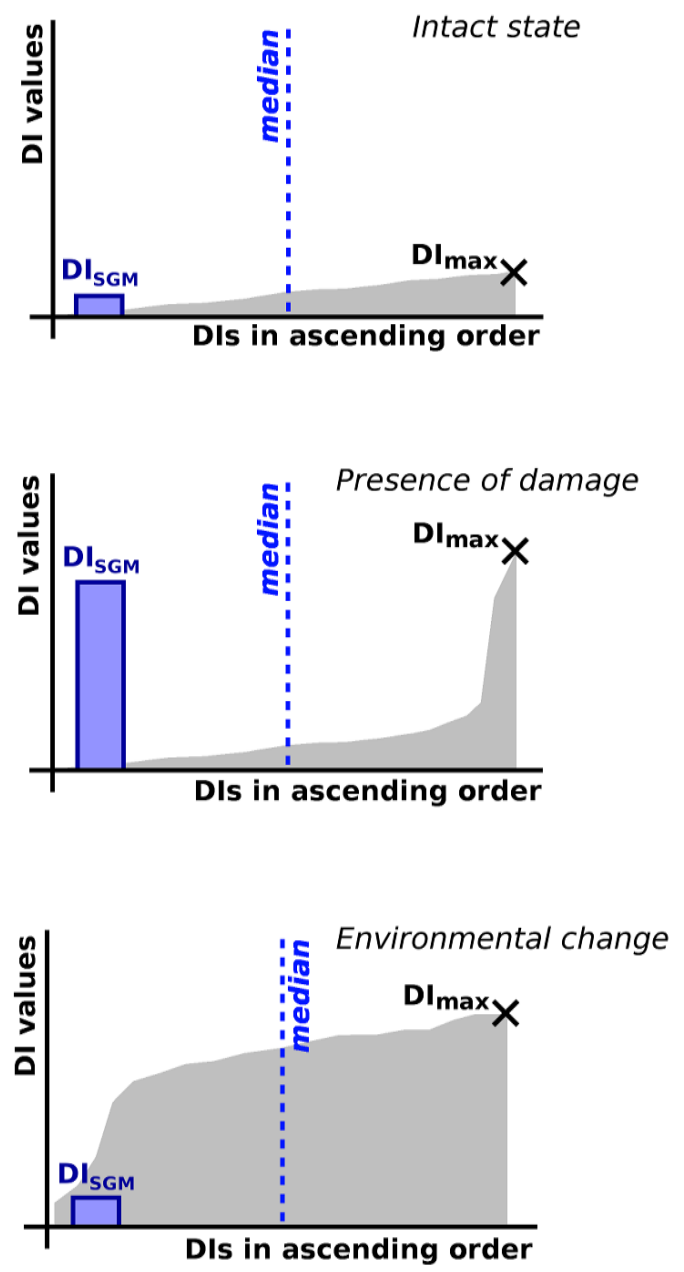

Fig. 2. Values of $\mathrm{DI}_{\mathrm{SGM}}$ in three typical monitoring scenarios

\section{SIMULATION VERIFICAITON}

The simulation verification was performed on the model that had a complex geometrical shape, was non-homogeneous (steel - aluminum) and had realistic boundary conditions. Thermal expansion phenomenon was included in simulation. The main goal of this stage was to investigate the influence of different temperature loadings on the modal filtration [13]. The geometrical model was created in MSC.Patran. Next the mesh hex- 8 elements (the no. of elements - approximately $10 \mathrm{k}$, nodes - 14k). In order to investigate the damaged frame behavior, a horizontal beam crack was modeled as node disconnectivity. There were two crack stadiums $5 \%$ and $10 \%$ of the cross section area. The model is presented in Figure 3.

In order to compare the temperature effect with the damaged frame behavior, a horizontal beam crack was modeled as node disconnectivity. There were two crack stadiums: $5 \%$ and $10 \%$ of the cross section area. Because the Young modulus varies with temperature, additional temperature-dependent material properties were applied. The material properties of aluminum were applied only to the horizontal beam. To take into account temperaturedependent material properties, each computation 
scenario was carried out in two sub-stages; first coupled mechanical-thermal analysis to obtain the temperature distribution, second - normal mode analysis. The following scenarios were analyzed.

1. $20^{\circ} \mathrm{C}$, uniform temperature, no crack.

2. $20^{\circ} \mathrm{C}$, uniform temperature, $5 \%$ crack.

3. $20^{\circ} \mathrm{C}$, uniform temperature, $10 \%$ crack.

4. $50^{\circ} \mathrm{C}$, upper beam heating $(30 \mathrm{~s})$, no crack.

5. $50^{\circ} \mathrm{C}$, local heating of the right vertical bar (30s), no crack.

6. $50{ }^{\circ} \mathrm{C}$, uniform temperature, no crack.

7. $-10{ }^{\circ} \mathrm{C}$, uniform temperature, no crack.

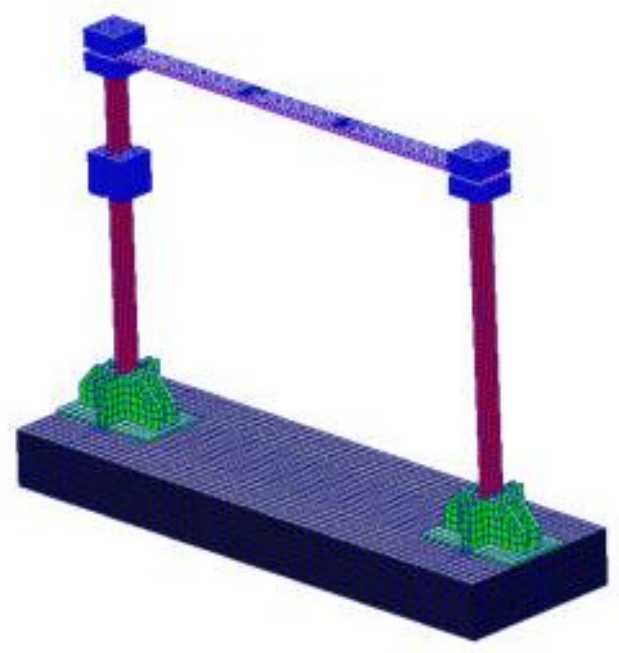

Fig. 3. FEM model used in simulations

The accelerations from 62 nodes evenly spaced along the structure were considered as a measured signals. The nodes (virtual sensors) were divided into 15 groups, 6 nodes in each group, with 2 nodes overlapping. For such a group definition the damage occurred in Group 7. For each group of nodes the local modal filter was identified. As the reference data the scenario without damage with the ambient temperature equal to $20{ }^{\circ} \mathrm{C}$ was used. Next for characteristics from every simulation scenario the local modal filtration was performed and damage indexes were calculated. In Figure 4 the damage index values for consecutive local modal filters (areas), for every simulation scenario are presented.

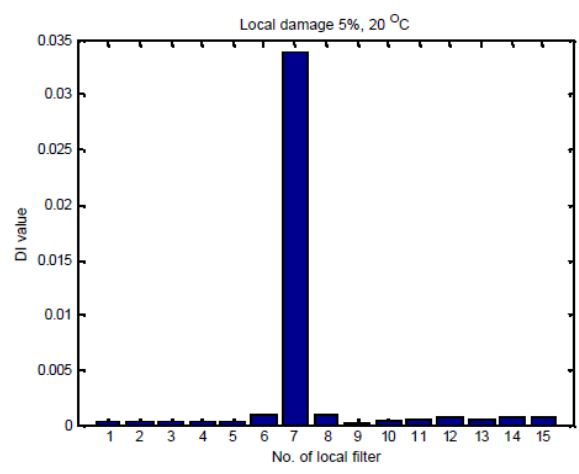

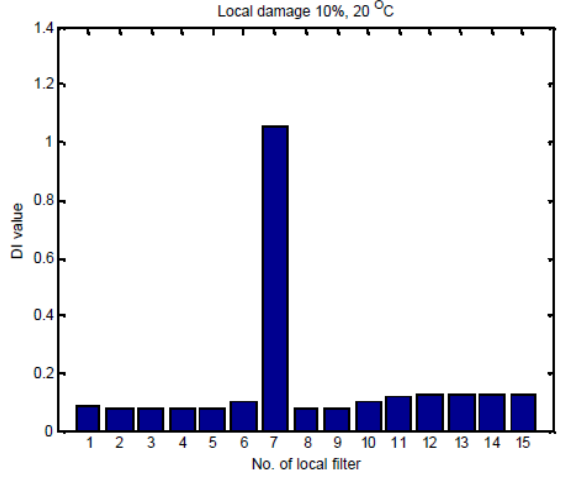
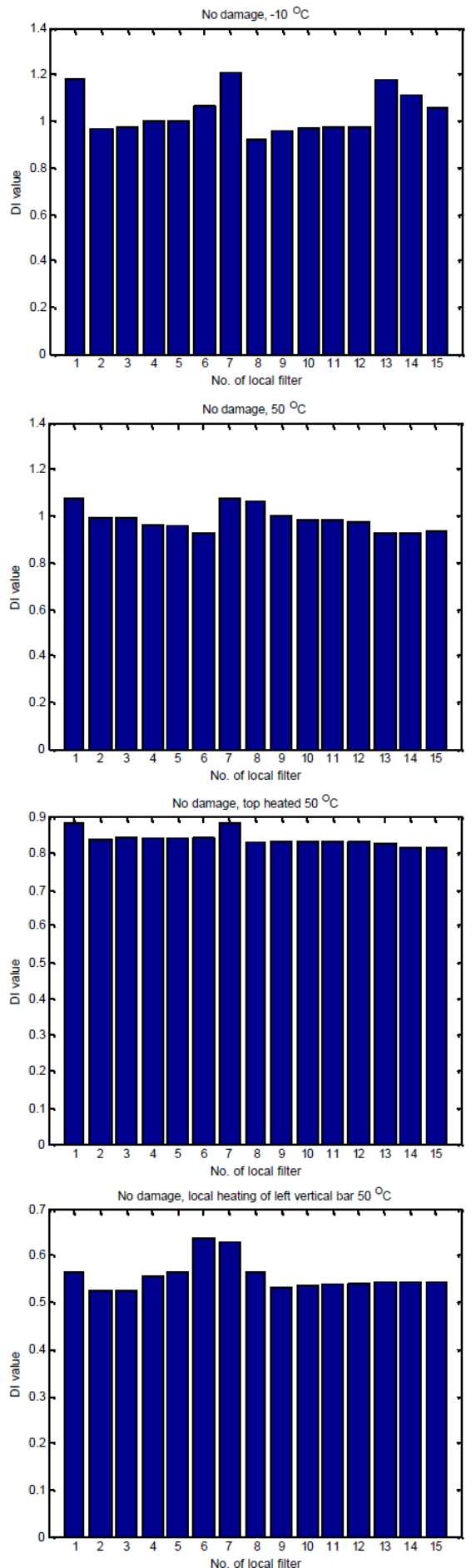

Fig. 4. Results of local modal filtration 
As it is clearly visible the performance of the local modal filters confirmed the authors assumptions. The damage cases showed significant growth of the DI value only for the local modal filter no. 7 - the damage was localized properly. For the other scenarios with ambient temperature variation growth of the DI values for all local filters was more less similar. It provides the possibility to distinguish between damage and other factors like ambient temperature or humidity change. It is also worth to mention that the scenario where frame was heated from above (simulation of ordinary sun operation) also did not revealed any changes between DI values calculated for local filters. It should be noted that values of the maximum DIs for all scenarios were comparable. The significant difference can be noticed only in the values distribution.

\section{TESTS ON EXPERIMENTAL DATA}

In order to further verify the assumptions described in Chapter 2, a laboratory experiment was carried out on a steel-aluminum frame. The frame was similar to one modelled for the numerical experiment. The following measuring equipment was used in the tests:

- electro-dynamic shaker K2004E01 with built-in power amplifier,

- piezoelectric PCB 333-B31 accelerometers,

- PCB 288-D01 impedance head,

- LMS Scadas III dynamic signal analyzer,

- a computer with LMS Test.Lab 10B installed

The laboratory stand used in the experiment is shown in Figure 5.

The measurements were carried out only on the upper beam of the frame, on which 21 measurement points were marked. The intervals between points amounted $40 \mathrm{~mm}$. The measurement consisted of 7 partial experiments.

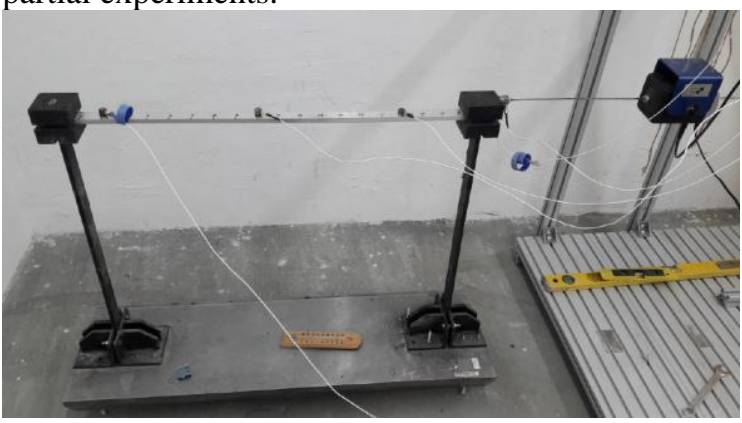

Fig. 5. Laboratory test stand

Four measurement scenarios were implemented:

1. undamaged beam at $25{ }^{\circ} \mathrm{C}$ - reference measurement,

2. undamaged beam at $45{ }^{\circ} \mathrm{C}$, frame was topheated with halogen lamps until the temperature stabilized,

3. beam at $25{ }^{\circ} \mathrm{C}$, with a $3 \mathrm{~mm}$ deep cut $(10 \%$ of the cross-sectional width) located between points 14 and 15 ,
4. beam at $25{ }^{\circ} \mathrm{C}$, with a $10 \mathrm{~mm}$ deep cut $(33 \%$ of the cross-sectional width) located between points 14 and 15 .

In the first stage, a modal analysis was performed on the data from the reference measurement (scenario No. 1). As a result, the first five modes of the studied structure were identified, from which 2, 3 and 4 were chosen to build local modal filters. They were between 50 and $150 \mathrm{~Hz}$ and this bandwidth was considered when comparing the characteristics in further studies. In practice, local spatial filters are designed to filter 2 to 4 initial modes. This is due to the fact that the number of sensors used to build an effective filter must be greater than the number of filtered modes [12]. If one uses filters tuned for filtration of a larger number of modes, the spatial resolution of damage localization would decrease significantly.

In the next step, modal filters were built, sequentially tuned to selected modes, in order to find the most sensitive one to the introduced damage. The results of modal filtration for subsequent modes are shown in Figure 6.

Obtained results clearly indicated that for further research it was best to use a modal filter set to the first mode shape (of the selected band second mode shape of the structure). For this modal filter, the damage yielded the highest DI values.

Then, the object was divided into areas, grouping together 5 neighboring measurement points. To increase the number of groups, and thus the spatial resolution of the method, with two-point overlap, was applied. With such a division, the damage was located in the group 5. The network of measurement points with division into groups and the marked place of damage is shown in Figure 7.

For the reference data (without damage, $20{ }^{\circ} \mathrm{C}$ ), local modal filters set to the $1^{\text {st }}$ mode shape were identified. Using these filters, the characteristics collected in subsequent test scenarios were filtered. On the basis of the obtained characteristics, the value of the DI was calculated. The results of local modal filtration for damage and temperature changes are shown in Figure 8.

Analyzing the obtained bar charts showing the DI values for particular groups, it was found that they are correct and in line with expectations. Index values referring to the temperature influence are low, with values similar for each group, while the damage shows a clear increase in the DI for the group No. 5, where the damage was located.

In the last stage the SGM approach was utilized. The values of $\mathrm{DI}_{\mathrm{SGM}}$ calculated for all three cases investigated are provided in Table 1. The difference between temperature change and large damage case is well pronounced. However, the $10 \%$ damage was not clearly detected probably due to relatively low influence of this fault on local modal vectors. Another reason for the small difference between the DI value for these cases was the need to implement each of the measurement scenarios in 7 partial experiments. 
Such frequent switching of sensors also caused the DI to increase beyond the fault area (see paper [16]).
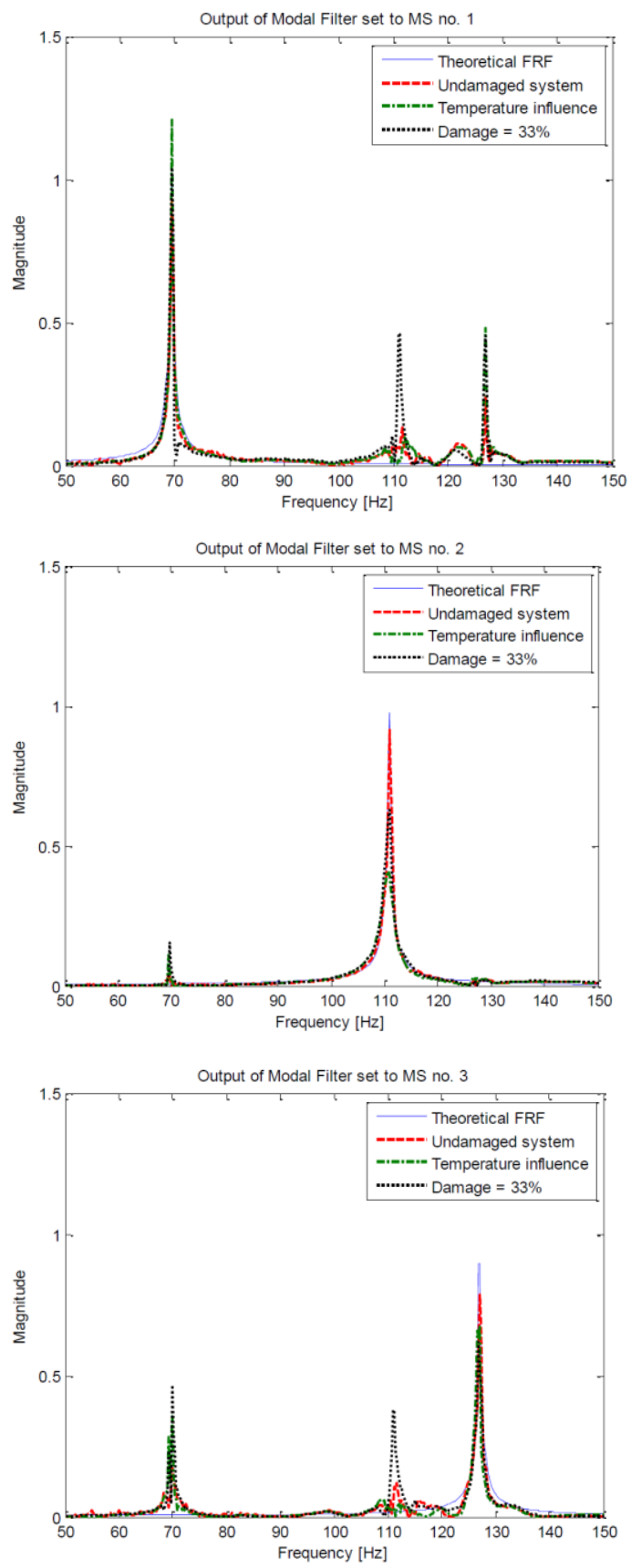

Fig. 6. Modal filtration results

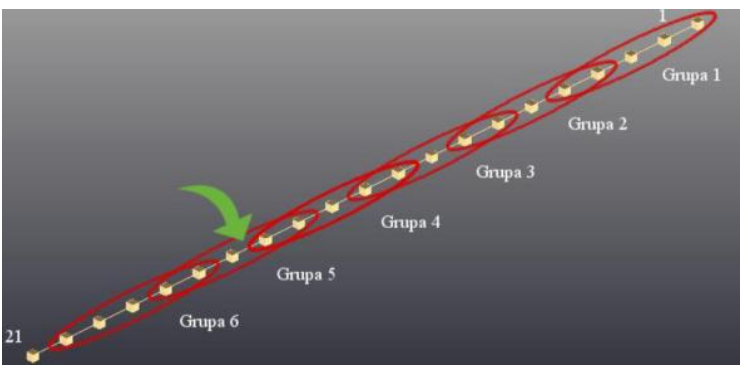

Fig. 7. Measurement points net. Arrow indicates location of the damage
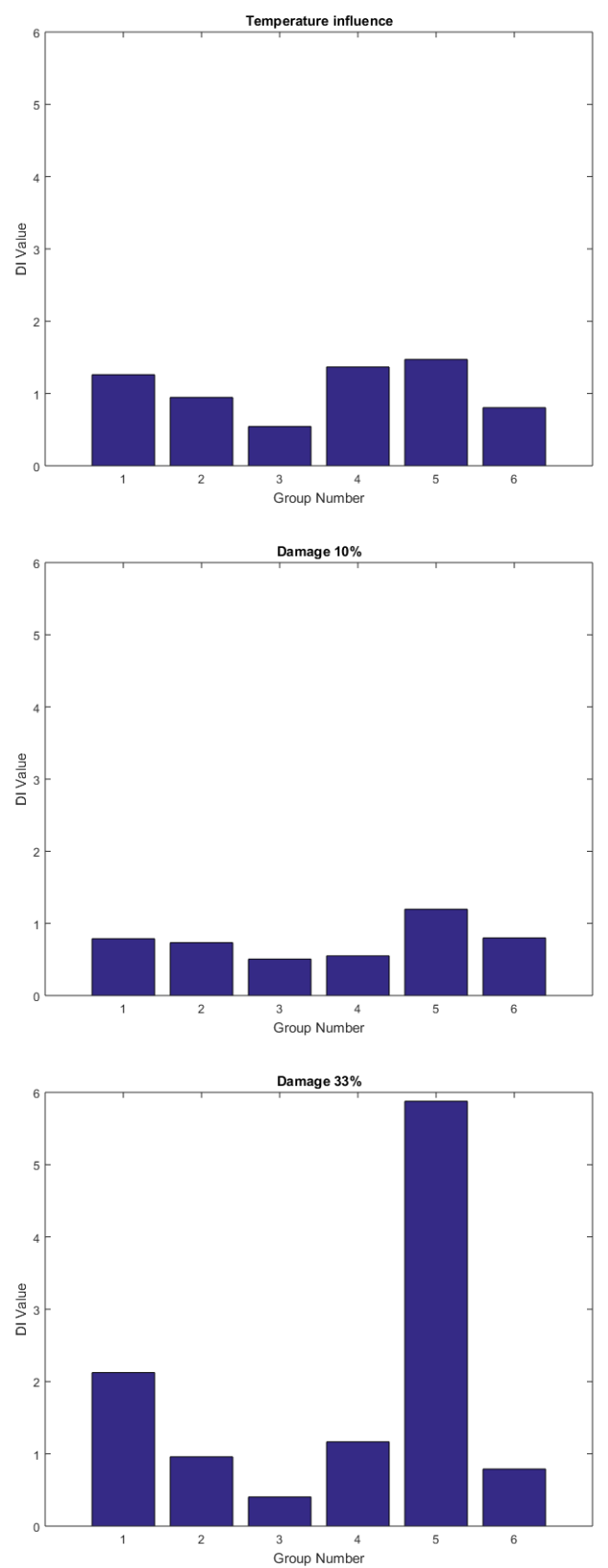

Fig. 8. Results of local modal filtration for experimental data

Table 1. Values of the indicator of the autonomous classifier

\begin{tabular}{|l|r|}
\hline Experiment scenerio & Value of the $\mathrm{DI}_{\text {SGM }}$ \\
\hline Temperature change & 0.3684 \\
\hline Damage 10\% & 0.4363 \\
\hline Damage 33\% & 4.8138 \\
\hline
\end{tabular}

Nevertheless, the tests carried out prove that the method of damage localization using local modal filters allows to separate the effects of ambient temperature changes and possibly other disturbances.

\section{SUMMARY}

The paper shows the differences between the operation of local modal filters in the case of 
changes in the outside temperature and damage. On this basis, an indicator was formulated using an autonomous method, which allows distinguishing the effect of damage from other disturbances. The assumptions and operation of the indicator were successfully verified on both numerical and experimental data. However, the results obtained from the laboratory data showed that the damage must be significant (above 10\%) to avoid false alarms. Before implementing the method in practice, it is necessary to fine-tune it (choosing the appropriate threshold) for the monitored facility. In further work it is planned to test robustness of the method for other factors e.g. mass change.

\section{REFERENCES}

1. Peeters B, Maeck J, De Roeck G. Dynamic monitoring of the Z24-bridge: separating temperature effects from damage. In Proceedings of the European COST F3 Conference on System Identification and Structural Health Monitoring. Madrid, Spain. 2000:377-386.

2. Furtmuller T, Adam C. Compensation of temperature effects in long-term monitoring of a highway bridge located in the Austrian Alps. Procedia Engineering. 2017; 199: 2078-2083. https://doi.org/10.1016/j.proeng.2017.09.477

3. Jeong-Tae Kim, Chung-Bang Yun, Jin-Hak Yi, Temperature effects on frequency-based damage detection in plate-girder bridges. KSCE Journal of Civil Engineering. 2003; 7: 725-733.

4. Yan A-M, Kerschen G, De Boe P, Golinval J-C. Structural damage diagnosis under varying environmental conditions - part I, II. Mechanical System and Signal Processing. 2005; 19: 847-880.

5. Nguyen VH, Mahowald J, Golinval JC, Maas S. Damage detection in civil engineering structure considering temperature effect. Dynamics of Civil Structures. 2014; 4: 187-196.

6. Basseville M, Bourquin F, Mevel L, Nasser H, Treyssède F. Handling the temperature effect in vibration monitoring: Two Subspace-Based Analytical Approaches. Journal of Engineering Mechanics. 2010; 136(3):367-378.

7. Zhou HF, Ni YQ, Ko J M. Eliminating temperature effect in vibration-based structural damage detection. Journal of Engineering Mechanics. 2012; 137(12): 785-796

8. Dao PB, Staszewski WJ. Cointegration approach for temperature effect compensation in Lamb-wavebased damage detection. Smart Materials and Structures. 2013; 22(9): 095002-1-095002-20.

9. Ambroziński, Ł, Magda, P, Stepinski, T. A method for compensation of the temperature effect disturbing Lamb waves propagation. 40th Annual Review of Progress in Quantitative Nondestructive Evaluation. 2014: 1157-1164. https://doi.org/10.1063/1.4864951

10. Dworakowski Z, Ambroziński Ł, Stepinski T. Multistage temperature compensation method for Lamb wave measurements. Journal of Sound and Vibration. 2016;382:328-339. https://doi.org/10.1016/j.jsv.2016.06.038

11. Salmanpour MS, Sharif Khodaei Z, Aliabadi MH. Guided wave temperature correction methods in structural health monitoring. Journal of Intelligent
Material Systems and Structures. 2017; 28(5): 604618. https://doi.org/10.1177/1045389X16651155

12. Zhang Q, Allemang RJ, Brown DL. Modal filter: Concept and applications. Proceedings of 8th IMAC, Orlando, FL, USA. 1990: 487-496.

13. Mendrok K, Uhl T. The application of modal filters for damage detection. Smart Structures and Systems. 2010; 6(2): 115-133.

14. Mendrok K, Uhl T. Experimental verification of the damage localization procedure based on modal filtering. Structural Health Monitoring. 2011; 10(2): 157-171.

15. Carrasco CJ, Osegueda RA, Ferregut CM, Grygier M. Damage localization in a space truss model using modal strain energy distribution. Proceedings of the15th International Modal Analysis Conference (IMAC), Orlando, Florida, 1997; Feb. 3-6: 17861792.

16. Mendrok K. Simulation verification of damage detection algorithm. Diagnostyka. 2010; 3:17-23.

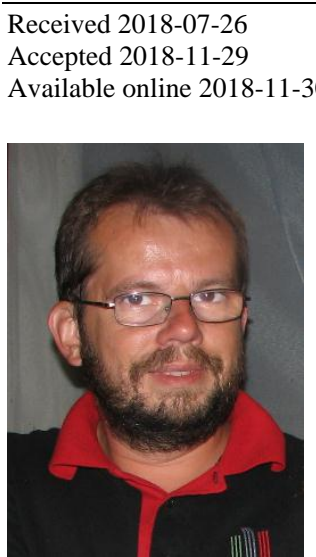

DSc. PhD. Krzysztof MENDROK

is an Associate Professor in the Department of Robotics and Mechatronice of the AGH University of Science and Technology. He is interested in development and application of various SHM algorithms. He mainly deals with low frequency vibration based methods for damage detection and inverse dynamic problem for excitation identification.

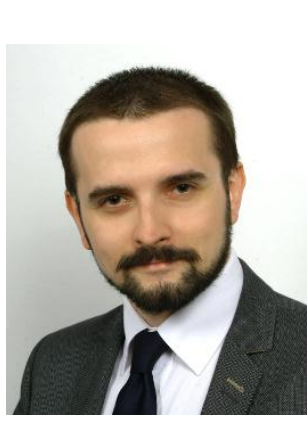

\section{PhD. Ziemowit DWORAKOWSKI}

Is a researcher in the Department of Robotics and Mechatronics of the AGH University of Science and Technology. His research interests include soft computing applied in mechanical engineering. Especially, he is interested in pattern recognition and novelty detection techniques for structural health monitoring data. 